\title{
Hydrothermal synthesis of visible light-sensitive conduction band-controlled tungsten-doped titanium dioxide photocatalysts with copper ion-grafts
}

\author{
Lei NI, Taiki KITTA, ${ }^{*}$ Naoya KUMAGAI, ${ }^{*}$ Bunsho OHTANI, ${ }^{* *}$ Kazuhito HASHIMOTO ${ }^{* * *}$ and Hiroshi IRIE ${ }^{\dagger}$ \\ Clean Energy Research Center, University of Yamanashi, 4-3-11 Takeda, Kofu 400-8511, Japan \\ *Interdisciplinary Graduate School of Medicine and Engineering, University of Yamanashi, 4-3-11 Takeda, Kofu 400-8511, Japan \\ ${ }^{* *}$ Catalysis Research Center, Hokkaido University, Sapporo 001-0021, Japan \\ ${ }^{* * * *}$ Research Center for Advanced Science and Technology, The University of Tokyo, \\ 4-6-1 Komaba, Meguro-ku, Tokyo 153-8904, Japan
}

\begin{abstract}
We prepared titanium dioxide $\left(\mathrm{TiO}_{2}\right)$ photocatalysts sensitive to visible light, namely copper(II) $[\mathrm{Cu}$ (II)]-grafted tungsten and gallium co-doped $\mathrm{TiO}_{2}\left(\mathrm{Ti}_{1-3 x} \mathrm{~W}_{x} \mathrm{Ga}_{2 x} \mathrm{O}_{2}, x\right.$ value is up to 0.12$)$, based on the concept of narrowing the band gap of $\mathrm{TiO}_{2}$ by positively shifting its conduction band $(\mathrm{CB})$ edge to a lower energy level and the catalytic multi-electron reduction of oxygen by $\mathrm{Cu}(\mathrm{I})$ ions [H. Yu, H. Irie, K. Hashimoto, J. Am. Chem. Soc., 132, 6898 (2010)]. Using this approach, the optical band-gap energy of $\mathrm{TiO}_{2}$ was decreased to $\sim 2.8 \mathrm{eV}$, and band-gap narrowing was confirmed by measuring the action spectrum for oxygen evolution from water in the presence of iron ions [ $\mathrm{Fe}(\mathrm{III})$, from $\left.\mathrm{FeCl}_{3}\right]$. The $\mathrm{Cu}$ (II)-grafted $\mathrm{Ti}_{1-3 x} \mathrm{~W}_{x} \mathrm{Ga}_{2 x} \mathrm{O}_{2}(x=0.12)$ photocatalyst effectively decomposed 2-propanol to carbon dioxide $\left(\mathrm{CO}_{2}\right)$ via acetone under visible light $\left(400-530 \mathrm{~nm}, 1 \mathrm{~mW} / \mathrm{cm}^{2}\right)$ with a $\mathrm{CO}_{2}$-generation rate of $0.30 \mu \mathrm{mol} / \mathrm{h}$. Grafting $\mathrm{Cu}$ (II) ions after the hydrochloric acid treatment of $\mathrm{Ti}_{1-3 x} \mathrm{~W}_{x} \mathrm{Ga}_{2 x} \mathrm{O}_{2}(x=0.12)$ increased the $\mathrm{CO}_{2}$-generation rate to $0.40 \mu \mathrm{mol} / \mathrm{h}$.
\end{abstract}

(C)2013 The Ceramic Society of Japan. All rights reserved.

Key-words: Titanium dioxide, Photocatalysis, Conduction band, Tungsten doping, Visible-light sensitivity, Cupper ion, Multi-electron oxygen reduction

[Received April 25, 2013; Accepted May 20, 2013]

\section{Introduction}

The development of titanium dioxide $\left(\mathrm{TiO}_{2}\right)$ photocatalysts with high sensitivity to visible light is needed to allow incoming light energy to be used more effectively, particularly for indoor applications. The main approaches for increasing the efficiency of light-energy conversion of $\mathrm{TiO}_{2}$ have involved either doping foreign elements into $\mathrm{TiO}_{2}{ }^{1-7)}$ or modifying $\mathrm{TiO}_{2}$ with absorbed molecules, such as the $\mathrm{Ru}$ complex ${ }^{8), 9)}$ and platinum chloride $\left(\mathrm{PtCl}_{4}\right.$ or $\left.\mathrm{H}_{2}\left[\mathrm{PtCl}_{6}\right]^{10), 11)}\right)$.

Recently, we demonstrated that $\mathrm{TiO}_{2}$ powder with grafted metal ions (copper(II) $[\mathrm{Cu}(\mathrm{II})]$ or iron(III) [Fe(III)]) is sensitive to visible light. ${ }^{12)-14)}$ This system functions photocatalytically, because the interfacial charge transfer (IFCT)-induced holes in the valence band $(\mathrm{VB})$ of $\mathrm{TiO}_{2}$ decompose organic substances, while the $\mathrm{Cu}(\mathrm{I})$ [or $\mathrm{Fe}(\mathrm{II})$ ] ions produced by IFCT appear to reduce adsorbed oxygen $\left(\mathrm{O}_{2}\right)$ through a multi-electron reduction process. ${ }^{12-14)}$ The induction of $\mathrm{O}_{2}$ reduction by photo-generated $\mathrm{Cu}(\mathrm{I})$ [or $\mathrm{Fe}(\mathrm{II})$ ] ions grafted on $\mathrm{TiO}_{2}$ enables the conduction band (CB) of $\mathrm{TiO}_{2}$ to be controlled, which led to the successful development of a visible light-sensitive CB-controlled $\mathrm{Cu}(\mathrm{II}) /$ $\mathrm{Ti}_{1-3 x} \mathrm{~W}_{x} \mathrm{Ga}_{2 x} \mathrm{O}_{2}$ photocatalyst. ${ }^{15)}$ In this system, $\mathrm{W}^{6+}$ (W $5 \mathrm{~d}$ ) contributes to the electronic structure of the $\mathrm{TiO}_{2} \mathrm{CB}$ bottom, which is mainly composed of $\mathrm{Ti} 3 \mathrm{~d}$, meaning that the $\mathrm{CB}$ consists of W $5 \mathrm{~d}$ and Ti $3 \mathrm{~d}$ hybrid orbitals, leading to band-gap narrowing. In addition, $\mathrm{Ga}^{3+}$ acts as a counter dopant to maintain charge neutrality, but the Ga 3d orbital does not contribute to either the

Corresponding author: H. Irie; E-mail: hirie@yamanashi.ac.jp
CB bottom or VB top. In a previous study, ${ }^{15)} \mathrm{Ti}_{1-3 x} \mathrm{~W}_{x} \mathrm{Ga}_{2 x} \mathrm{O}_{2}$ was prepared using a pseudo-solid solution method; however, the highest $x$ value achieved was only 0.05 . To further enhance the visible-light absorption of this photocatalyst, further optimization of the preparation method is required to introduce larger amounts of $\mathrm{W}^{6+}$ and $\mathrm{Ga}^{3+}$ ions.

In the present study, we attempted to enhance the visible-light absorption capability of $\mathrm{Ti}_{1-3 x} \mathrm{~W}_{x} \mathrm{Ga}_{2 x} \mathrm{O}_{2}$ using a hydrothermal method to increase the $x$ values of this photocatalyst. Using this approach, $\mathrm{Ti}_{1-3 x} \mathrm{~W}_{x} \mathrm{Ga}_{2 x} \mathrm{O}_{2}$ photocatalysts with $x$ values up to 0.12 were prepared and characterized. Specifically, the photocatalytic oxidation activities of the prepared photocatalysts were assessed using 2-propanol decomposition reaction after the grafting of $\mathrm{Cu}(\mathrm{II})$ ions and by measuring the action spectrum of bare $\mathrm{Ti}_{1-3 x} \mathrm{~W}_{x} \mathrm{Ga}_{2 x} \mathrm{O}_{2}$ for $\mathrm{O}_{2}$ evolution in the presence of $\mathrm{a}$ sacrificial agent $[\mathrm{Fe}(\mathrm{III})]$.

\section{Experimental}

$\mathrm{Ti}_{1-3 x} \mathrm{~W}_{x} \mathrm{Ga}_{2 x} \mathrm{O}_{2}(x=0,0.03,0.05,0.07,0.08,0.10$, and 0.12) was synthesized using a hydrothermal method. Stoichiometric amounts of $\mathrm{Ti}\left(\mathrm{SO}_{4}\right)_{2}$ (Kanto Kagaku) and $\mathrm{Na}_{2} \mathrm{WO}_{4}$ (Kanto Chemical), and an excess amount of $\mathrm{Ga}\left(\mathrm{NO}_{3}\right)_{3} \cdot n \mathrm{H}_{2} \mathrm{O}(n=7-9$; $n$ was assumed to be 8 , which is 1.5 times larger than the stoichiometric amount; High Purity Chemicals) were mixed in $180 \mathrm{~mL}$ distilled water, stirred for $0.5 \mathrm{~h}$, and then heated at $140^{\circ} \mathrm{C}$ for $12 \mathrm{~h}$ in a $300-\mathrm{mL}$ Teflon-lined stainless steel autoclave. The suspension was then centrifuged and the obtained yellowish precipitates were washed with a sufficient amount of distilled water. The centrifugal and washing steps were repeated four 
times, and the obtained precipitates were dried at $80^{\circ} \mathrm{C}$ in a drying oven. The resulting powders were heated at $600^{\circ} \mathrm{C}$ for $2 \mathrm{~h}$, and then further heated either at 780 or $900^{\circ} \mathrm{C}$ for $24 \mathrm{~h}$. In the case of $\mathrm{Ti}_{1-3 x} \mathrm{~W}_{x} \mathrm{Ga}_{2 x} \mathrm{O}_{2}(x=0.12)$, the dried powder was further washed with diluted $\mathrm{HCl}$ once and distilled water repeatedly four times, and then dried at $80^{\circ} \mathrm{C}$ in a dry oven.

$\mathrm{Cu}(\mathrm{II}) / \mathrm{Ti}_{1-3 x} \mathrm{~W}_{x} \mathrm{Ga}_{2 x} \mathrm{O}_{2}$ photocatalyst was prepared by the same impregnation method used in our previous report, ${ }^{12), 13)}$ using copper chloride $\left(\mathrm{CuCl}_{2} \cdot 2 \mathrm{H}_{2} \mathrm{O}\right.$, Aldrich) as the source of $\mathrm{Cu}(\mathrm{II})$. Briefly, $1 \mathrm{~g}$ of $\mathrm{Ti}_{1-3 x} \mathrm{~W}_{x} \mathrm{Ga}_{2 x} \mathrm{O}_{2}$ powder was dispersed in $10 \mathrm{~mL}$ distilled water. $\mathrm{CuCl}_{2} \cdot 2 \mathrm{H}_{2} \mathrm{O}$ was added to the aqueous $\mathrm{Ti}_{1-3 x} \mathrm{~W}_{x} \mathrm{Ga}_{2 x} \mathrm{O}_{2}$ suspension at a weight fraction of $\mathrm{Cu}$ relative to $\mathrm{Ti}_{1-3 x} \mathrm{~W}_{x} \mathrm{Ga}_{2 x} \mathrm{O}_{2}$ of $1.0 \times 10^{-3}$, as this fraction displayed the highest activity for the decomposition of 2-propanol in the case of $\mathrm{Cu}(\mathrm{II}) / \mathrm{TiO}_{2}$ in our preliminary tests. ${ }^{15)}$ The resulting suspension was heated to $90^{\circ} \mathrm{C}$ under stirring for $1 \mathrm{~h}$ in a vial reactor. The suspension was then filtered twice through a $0.025-\mu \mathrm{m}$ membrane filter (Millipore) and washed with copious amounts of distilled water. The residues were dried at $110^{\circ} \mathrm{C}$ for $24 \mathrm{~h}$ and then ground into a fine powder using an agate mortar.

The crystal structures of the prepared $\mathrm{Ti}_{1-3 x} \mathrm{~W}_{x} \mathrm{Ga}_{2 x} \mathrm{O}_{2}$ powders were determined by X-ray diffraction (XRD; Panalytical PW1700). The morphology of the $\mathrm{Ti}_{1-3 x} \mathrm{~W}_{x} \mathrm{Ga}_{2 x} \mathrm{O}_{2}$ samples was investigated by field emission scanning electron microscopy (FESEM; S-4500, Hitachi). UV-visible absorption spectra were measured by a diffuse reflection method using a V-650 spectrometer (JASCO). Brunauer-Emmett-Teller (BET) surface areas were determined using a Micromeritics TriStar 3000 nitrogen adsorption apparatus (Shimadzu).

$\mathrm{O}_{2}$ evolution was measured in the presence of bare $\mathrm{Ti}_{1-3 x} \mathrm{~W}_{x^{-}}$ $\mathrm{Ga}_{2 x} \mathrm{O}_{2}(x=0$ and $0.10,30 \mathrm{mg})$ with the aid of $\mathrm{Fe}(\mathrm{III})$ [iron chloride $\left(\mathrm{FeCl}_{3}\right)$; Kanto Kagaku, $\left.0.01 \mathrm{~mol} / \mathrm{L}\right]$ as a sacrificial agent. The measurements were performed in $3 \mathrm{~mL}$ water, without adjusting the solution $\mathrm{pH}$, while stirring using a magnetic stirrer under monochromatic light $(360 \pm 5,390 \pm 5,420 \pm 5$, $430 \pm 5,450 \pm 5$, and $480 \pm 5 \mathrm{~nm})$ generated by a diffraction grating-type illuminator (CRM-FD, Jasco) equipped with a 300W xenon (Xe) lamp (C2578-02, Hamamatsu Photonics). Higherorder diffracted light was cutoff with an appropriate optical filter.

The photocatalytic activity of the prepared powders was evaluated by monitoring 2-propanol gas decomposition under visiblelight irradiation, as described in our previous report.4),12)-16) Briefly, visible light $\left(1 \mathrm{~mW} \mathrm{~cm}{ }^{-2}, 400-530 \mathrm{~nm}\right)$ from an Xe lamp (Luminar Ace 210, Hayashi Tokei Works) and a combination of optical filters (B-46, L-42, and C-40C, Hoya) was used to irradiate a $300-\mathrm{mg}$ sample of each prepared $\mathrm{Cu}(\mathrm{II}) / \mathrm{Ti}_{1-3 x} \mathrm{~W}_{x^{-}}$ $\mathrm{Ga}_{2 x} \mathrm{O}_{2}$ photocatalyst, which was uniformly spread over the irradiation area $\left(\sim 5.5 \mathrm{~cm}^{2}\right)$ in a $500-\mathrm{mL}$ quartz vessel. Prior to irradiation, the vessel was evacuated and filled with synthetic air. To eliminate organic contaminants on the sample surface, the sample was irradiated with visible light until the rate of $\mathrm{CO}_{2}-$ generation was less than $0.02 \mu \mathrm{mol} /$ day. The vessel was then reevacuated and filled with synthetic air, followed by the injection of $6.1 \mu \mathrm{mol}(300 \mathrm{ppm})$ of the reactant gas. The samples were kept in the dark until the gas concentration reached a constant level, as this indicated that the adsorption of 2-propanol gas onto the powder surface was complete. Visible-light irradiation was then started, and the concentrations of produced acetone and $\mathrm{CO}_{2}$ were monitored using a gas chromatograph (GC-8A, Shimadzu).

\section{Results and discussion}

Figure 1(a) shows the XRD patterns of the prepared $\mathrm{Ti}_{1-3 x} \mathrm{~W}_{x^{-}}$ $\mathrm{Ga}_{2 x} \mathrm{O}_{2}(x=0,0.03,0.05,0.07$, and 0.08$)$ powders after
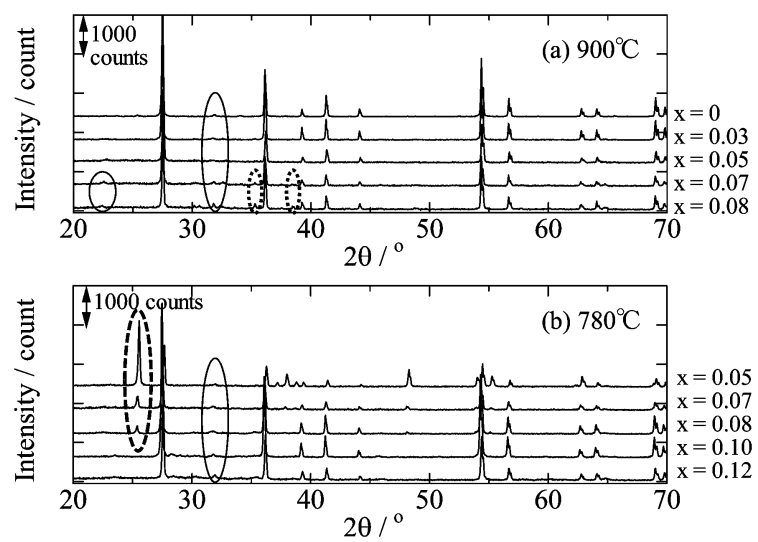

Fig. 1. XRD patterns of $\mathrm{Ti}_{1-3 x} \mathrm{~W}_{x} \mathrm{Ga}_{2 x} \mathrm{O}_{2}$ calcined at (a) $900^{\circ} \mathrm{C}$ and (b) $780^{\circ} \mathrm{C}$. The broken circles in (b) and solid circles in (a) and (b) indicate the phases of anatase $\mathrm{TiO}_{2}$ and polymorphous titanium oxide (either $\mathrm{Ti}_{4} \mathrm{O}_{7}$ or $\mathrm{Ti}_{5} \mathrm{O}_{9}$ ), respectively. The dot circles in (a) indicate that of $\mathrm{Ga}_{2} \mathrm{O}_{3}$.

Table 1. Phases of the prepared photocatalysts with increasing $x$ value after calcination at 780 and $900^{\circ} \mathrm{C}$

\begin{tabular}{lcc}
\hline \multicolumn{1}{c}{$x$} & $780^{\circ} \mathrm{C}$ & $900^{\circ} \mathrm{C}$ \\
\hline 0 & - & $\mathrm{R}$ \\
0.03 & - & $\mathrm{R}$ \\
0.05 & $\mathrm{R}<\mathrm{A}$ & $\mathrm{R}$ \\
0.07 & $\mathrm{R}>\mathrm{A}$ & $\mathrm{R}+\mathrm{Ga}_{2} \mathrm{O}_{3}$ \\
0.08 & $\mathrm{R} \gg \mathrm{A}$ & $\mathrm{R}+\mathrm{Ga}_{2} \mathrm{O}_{3}$ \\
0.10 & $\mathrm{R}$ & - \\
0.12 & $\mathrm{R}$ & - \\
\hline
\end{tabular}

$\mathrm{A}$ and $\mathrm{R}$ denote anatase and rutile phases, respectively.

All photocatalysts contain a trace amount of either $\mathrm{Ti}_{4} \mathrm{O}_{7}$ or $\mathrm{Ti}_{5} \mathrm{O}_{9}$.

calcination at $900^{\circ} \mathrm{C}$. The powders with $x=0,0.03$, and 0.05 displayed a tetragonal crystal system with rutile $\mathrm{TiO}_{2}$ crystallinity. However, in the $x=0.07$ and 0.08 samples, a trace amount of $\mathrm{Ga}_{2} \mathrm{O}_{3}$ as an impurity was observed. At a lower calcination temperature $\left(780^{\circ} \mathrm{C}\right)$, the XRD patterns of the $\mathrm{Ti}_{1-3 x} \mathrm{~W}_{x} \mathrm{Ga}_{2 x} \mathrm{O}_{2}$ $(x=0.05,0.07,0.08,0.10$, and 0.12$)$ powders revealed that the rutile and anatase phases increased and decreased, respectively, with increasing $x$ values [Fig. 1(b)] and that a rutile phase was obtained in photocatalysts with $x=0.10$ and 0.12 [Fig. 1(b)]. Note that all powders contained a small amount of polymorphous titanium oxide (either $\mathrm{Ti}_{4} \mathrm{O}_{7}$ or $\mathrm{Ti}_{5} \mathrm{O}_{9}$ ). However, the existence of such titanium oxide would be negligible because of its trace amount. The phase compositions of the prepared photocatalysts are summarized in Table $\mathbf{1}$.

FE-SEM images of $\mathrm{Ti}_{1-3 x} \mathrm{~W}_{x} \mathrm{Ga}_{2 x} \mathrm{O}_{2}$ powders $(x=0.05$ and 0.12 ) after calcination at 900 and $780^{\circ} \mathrm{C}$ are shown in Figs. 2(a) and 2(b), respectively. The particles of $\mathrm{Ti}_{1-3 x} \mathrm{~W}_{x} \mathrm{Ga}_{2 x} \mathrm{O}_{2}(x=$ 0.05 ) ranged in size from 1-3 $\mu \mathrm{m}$ and appeared rounded with dull edges, and were well crystallized with a surface step structure. In contrast, those of $x=0.12$ were more slender in shape with sizes of $\sim 0.5 \mu \mathrm{m} \times 3 \mu \mathrm{m}$. Calcination decreased the surface area of the $\mathrm{Ti}_{1-3 x} \mathrm{~W}_{x} \mathrm{Ga}_{2 x} \mathrm{O}_{2}(x=0.12)$ powder from 107 to $2.56 \mathrm{~m}^{2} / \mathrm{g}$.

The UV-visible absorption spectra of the prepared $\mathrm{Ti}_{1-3 x} \mathrm{~W}_{x^{-}}$ $\mathrm{Ga}_{2 x} \mathrm{O}_{2}$ photocatalysts were measured by the diffuse reflection method (Fig. 3). The spectra for the photocatalysts calcined at $900^{\circ} \mathrm{C}$ indicated that the doping of $\mathrm{W}^{6+}$ (and $\mathrm{Ga}^{3+}$ ) at $\mathrm{Ti}^{4+}$ sites narrowed the band-gap of rutile $\mathrm{TiO}_{2}$ and shifted the absorption edges to a longer wavelength region [Fig. 3(a)]. Notably, the 

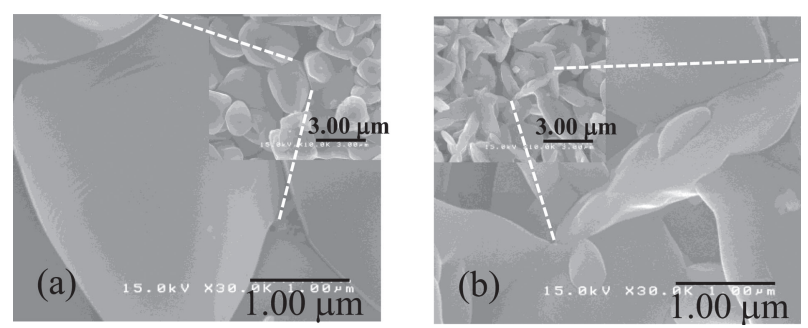

Fig. 2. FE-SEM images of (a) $\mathrm{Ti}_{1-3 x} \mathrm{~W}_{x} \mathrm{Ga}_{2 x} \mathrm{O}_{2}(x=0.05)$ calcined at $900^{\circ} \mathrm{C}$ and (b) $\mathrm{Ti}_{1-3 x} \mathrm{~W}_{x} \mathrm{Ga}_{2 x} \mathrm{O}_{2}(x=0.12)$ calcined at $780^{\circ} \mathrm{C}$. The insets are low-magnification images.
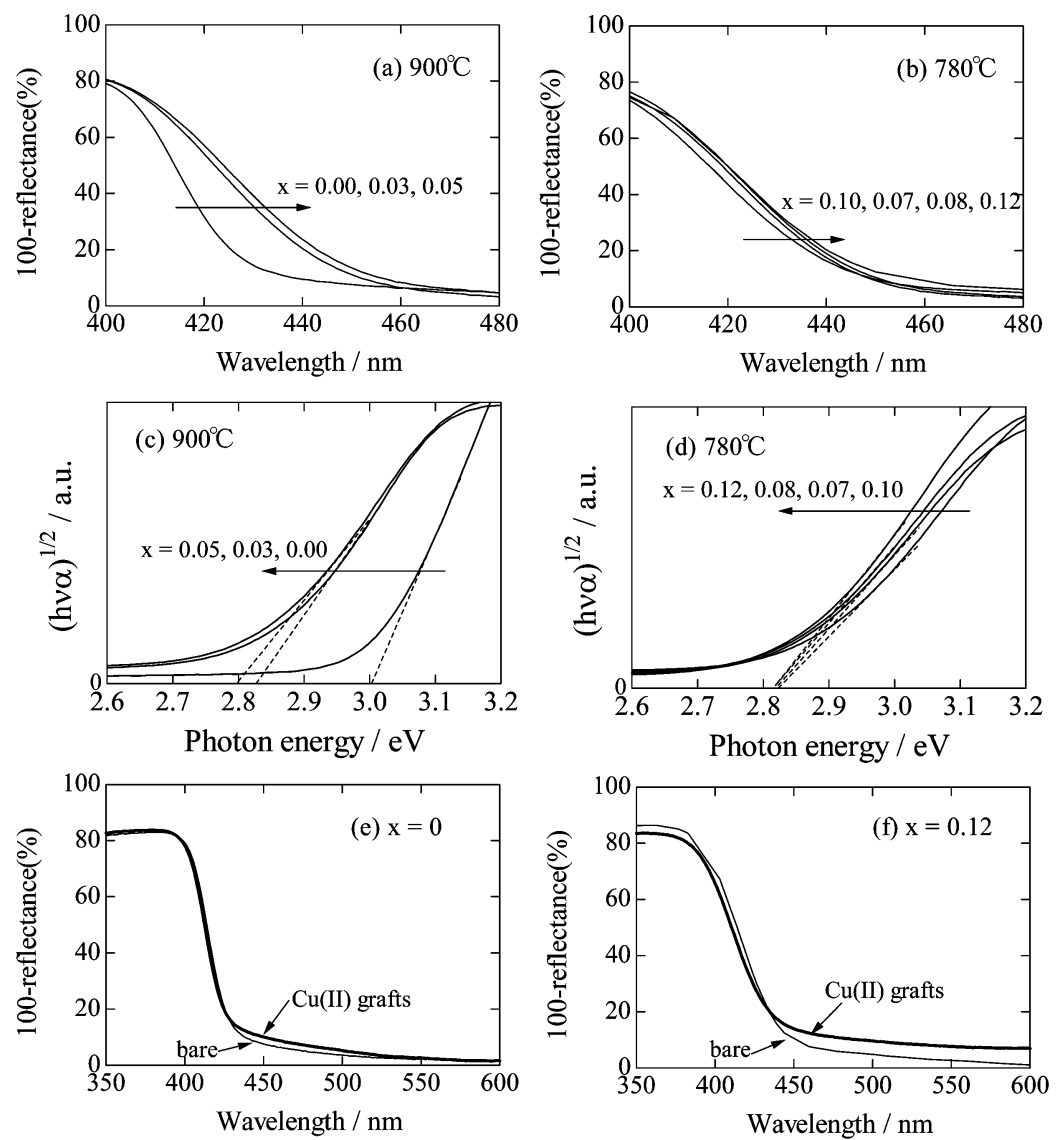

Fig. 3. UV-visible diffuse reflectance spectra of (a) $\mathrm{Ti}_{1-3 x} \mathrm{~W}_{x} \mathrm{Ga}_{2 x} \mathrm{O}_{2}(x=0,0.03$, and 0.05$)$ calcined at $900^{\circ} \mathrm{C}$ and (b) $\mathrm{Ti}_{1-3 x} \mathrm{~W}_{x} \mathrm{Ga}_{2 x} \mathrm{O}_{2}(x=0.07,0.08,0.10$, and 0.12$)$ calcined at $780^{\circ} \mathrm{C}$. The respective plots of the square root of the KubelkaMunk function for (a) and (b) against photon energy are shown in (c) and (d). The UV-vis diffuse reflectance of Cu(II)/ $\mathrm{Ti}_{1-3 x} \mathrm{~W}_{x} \mathrm{Ga}_{2 x} \mathrm{O}_{2}$ [(e) $x=0$ and (f) $\left.x=0.12\right]$ are presented as examples.

photocatalysts maintained rutile $\mathrm{TiO}_{2}$ crystallinity until $x=0.05$. However, the spectra for the photocatalysts calcined at $780^{\circ} \mathrm{C}$ did not exhibit any marked changes up to $x=0.12$ [Fig. 3(b)]. A small amount of anatase was present in the photocatalysts with $x=0.07$ and 0.08 ; however, because the band-gap of anatase $(3.2 \mathrm{eV})$ is larger than that of rutile $\mathrm{TiO}_{2}(3.0 \mathrm{eV})$, the effect of anatase on the UV-visible absorption spectrum would be negligible. As rutile $\mathrm{TiO}_{2}$ is an indirect gap semiconductor, the bandgap of $\mathrm{Ti}_{1-3 x} \mathrm{~W}_{x} \mathrm{Ga}_{2 x} \mathrm{O}_{2}$ can be estimated from the tangent lines in plots of the square root of the Kubelka-Munk functions against the photon energy, ${ }^{17)}$ as shown in Figs. 3(c) and 3(d). Using this approach, the band-gap energies of $\mathrm{Ti}_{1-3 x} \mathrm{~W}_{x} \mathrm{Ga}_{2 x} \mathrm{O}_{2}$ determined from the tangent lines, which were extrapolated to $(\mathrm{h} v \alpha)^{1 / 2}=0$, remained constant at approximately $2.8 \mathrm{eV}$ (Fig. 4). To confirm the grafting of $\mathrm{Cu}(\mathrm{II})$ ions, the UV-vis diffuse reflectance spectra of $x=0$ and 0.12 in $\mathrm{Cu}(\mathrm{II}) / \mathrm{Ti}_{1-3 x} \mathrm{~W}_{x} \mathrm{Ga}_{2 x} \mathrm{O}_{2}$ were also shown as examples [Figs. 3(e) and 3(f), respectively], as the spectra of all other prepared photocatalysts were similar to that of the $x=0.12$ photocatalyst. The corresponding spectra of ungrafted (bare) samples in Figs. 3(a) and 3(b) are also shown as a comparison. The slight increase in the $420-550-\mathrm{nm}$ wavelength region in the spectrum of $\mathrm{Cu}(\mathrm{II}) / \mathrm{Ti}_{1-3 x} \mathrm{~W}_{x} \mathrm{Ga}_{2 x} \mathrm{O}_{2}(x=0)$ can be assigned to IFCT of VB electrons to surface-grafted $\mathrm{Cu}(\mathrm{II})$, as we reported previously for $\mathrm{Cu}(\mathrm{II}) / \mathrm{TiO}_{2} \cdot{ }^{12), 13), 15)}$ In contrast, the absorption slightly increased above $\sim 440 \mathrm{~nm}$ in the spectrum of $\mathrm{Cu}(\mathrm{II}) / \mathrm{Ti}_{1-3 x} \mathrm{~W}_{x} \mathrm{Ga}_{2 x} \mathrm{O}_{2} \quad(x=1.2)$, a result that may reflect 


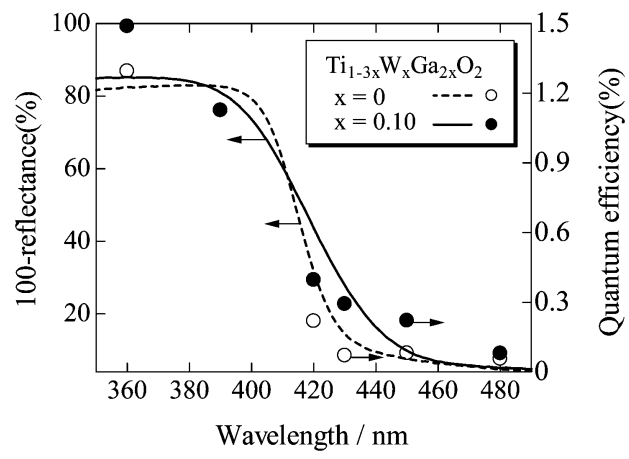

Fig. 5. Action spectra for $\mathrm{O}_{2}$ evolution by $\mathrm{Ti}_{1-3 x} \mathrm{~W}_{x} \mathrm{Ga}_{2 x} \mathrm{O}_{2}(x=0.10$, closed circles; and $x=0$, open circles) in an aqueous Fe(III) solution. UV-visible absorption spectra for $x=0.10$ (black line) and $x=0$ (broken line) are also shown.

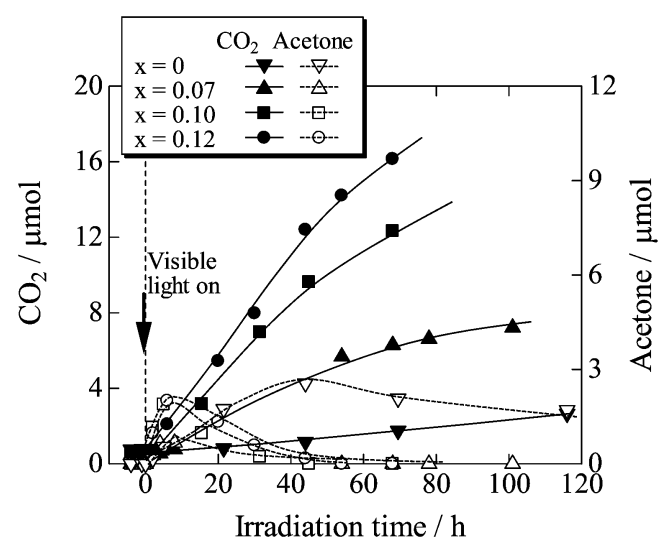

Fig. 6. Changes in acetone and $\mathrm{CO}_{2}$ amounts as a function of time during 2-propanol oxidation by $\mathrm{Ti}_{1-3 x} \mathrm{~W}_{x} \mathrm{Ga}_{2 x} \mathrm{O}_{2}(x=0,0.07,0.10$, and $0.12)$.

experimental error. A slight increase was expected in the 440 $550-\mathrm{nm}$ region on comparison with the spectra of $\mathrm{Ti}_{1-3 x} \mathrm{~W}_{x^{-}}$ $\mathrm{Ga}_{2 x} \mathrm{O}_{2}(x=0)$ with and without $\mathrm{Cu}(\mathrm{II})$ grafts because it is reasonable to assume that the absorption due to IFCT at 420 $440 \mathrm{~nm}$ was masked by interband transition.

The action spectrum for $\mathrm{O}_{2}$ evolution by $\mathrm{Ti}_{1-3 x} \mathrm{~W}_{x} \mathrm{Ga}_{2 x} \mathrm{O}_{2}$ $(x=0.10)$ photocatalyst in aqueous $\mathrm{Fe}(\mathrm{III})$ solution (Fig. 5) confirmed that the photocatalyst was able to utilize visible light up to $\sim 480 \mathrm{~nm}$. Importantly, the apparent quantum efficiency (QE) values for this material under irradiation with both UV (360 and $390 \mathrm{~nm})$ and visible light $(420-480 \mathrm{~nm})$ coincided with the $\mathrm{UV}-$ visible spectrum, indicating that $\mathrm{Ti}_{1-3 x} \mathrm{~W}_{x} \mathrm{Ga}_{2 x} \mathrm{O}_{2}(x=0.10)$ certainly underwent band-gap narrowing. ${ }^{18)}$ The spectrum for $\mathrm{O}_{2}$ evolution by $\mathrm{Ti}_{1-3 x} \mathrm{~W}_{x} \mathrm{Ga}_{2 x} \mathrm{O}_{2}(x=0)$ was also measured (Fig. 5). As rutile $\mathrm{TiO}_{2}$ has a band gap of $3.0 \mathrm{eV}$, it is reasonable that the photocatalyst was inactive upon irradiation with visible light at wavelengths longer than $430 \mathrm{~nm}$.

Figure 6 shows the changes in the amounts of acetone and $\mathrm{CO}_{2}$ of 2-propanol oxidation tests for $\mathrm{Cu}(\mathrm{II}) / \mathrm{Ti}_{1-3 x} \mathrm{~W}_{x} \mathrm{Ga}_{2 x} \mathrm{O}_{2}$ $(x=0,0.07,0.10$, and 0.12$)$ under visible-light irradiation. In all of the tests, including those with $\mathrm{Cu}(\mathrm{II}) / \mathrm{Ti}_{1-3 x} \mathrm{~W}_{x} \mathrm{Ga}_{2 x} \mathrm{O}_{2}$, the profiles of acetone and $\mathrm{CO}_{2}$-generation were characterized by initial increases in the acetone concentration, which then began to decrease, accompanied by $\mathrm{CO}_{2}$ production. This behavior is plausible, as 2-propanol decomposes into $\mathrm{CO}_{2}$, which is the final product, via acetone, the intermediary product. ${ }^{19)}$ The number of
Table 2. Number of absorbed photons, $\mathrm{CO}_{2}$-generation rate, and QEs for 2-propanol decomposition by $\mathrm{Cu}(\mathrm{II}) / \mathrm{Ti}_{1-3 x} \mathrm{~W}_{x} \mathrm{Ga}_{2 x} \mathrm{O}_{2}$ and $\mathrm{Cu}(\mathrm{II}) / \mathrm{WO}_{3}$

\begin{tabular}{lccc}
\hline \multicolumn{1}{c}{$x$} & $\begin{array}{c}\text { Flux of absorbed } \\
\text { photons } / \mathrm{s}^{-1}\end{array}$ & $\begin{array}{c}\mathrm{CO}_{2} \text {-generation rate } \\
/ \mu \mathrm{molh}\end{array}$ & $\mathrm{QE}(\%)$ \\
\hline 0 & $1.0 \times 10^{15}$ & $1.6 \times 10^{-1}$ & 16 \\
0.03 & $2.0 \times 10^{15}$ & $2.1 \times 10^{-1}$ & 10 \\
0.05 & $2.0 \times 10^{15}$ & $1.3 \times 10^{-1}$ & 6.5 \\
0.07 & $1.8 \times 10^{15}$ & $1.2 \times 10^{-1}$ a) & 6.7 \\
0.08 & $1.9 \times 10^{15}$ & $2.3 \times 10^{-1}$ & 12 \\
0.10 & $1.8 \times 10^{15}$ & $\left.2.5 \times 10^{-1} \mathrm{a}\right)$ & 14 \\
0.12 & $1.8 \times 10^{15}$ & $\left.3.0 \times 10^{-1} \mathrm{a}\right)$ & 17 \\
& & $\left.\left.4.0 \times 10^{-1} \mathrm{a}\right), \mathrm{b}\right)$ & $22^{\mathrm{b})}$ \\
\hline $\mathrm{WO}_{3}$ & $4.2 \times 10^{15}$ & $4.8 \times 10^{-1}$ & 11 \\
\hline
\end{tabular}

a) Average values for two photocatalytic decomposition tests.

b) $\mathrm{Cu}$ (II) ions were grafted after $\mathrm{HCl}$ treatment of the photocatalyst.

absorbed photons, $\mathrm{CO}_{2}$-generation rates, and $\mathrm{QE}$ values for the decomposition of 2-propanol by the photocatalysts are presented in Table 2. The QE value was estimated based on the assumption that six photons are required to produce one $\mathrm{CO}_{2}$ molecule, as represented in the formula: $\mathrm{C}_{3} \mathrm{H}_{8} \mathrm{O}+5 \mathrm{H}_{2} \mathrm{O}+18 \mathrm{~h}^{+} \rightarrow 3 \mathrm{CO}_{2}+$ $18 \mathrm{H}^{+}$. The $\mathrm{QE}$ value for $\mathrm{CO}_{2}$-generation was calculated using the equation: $\mathrm{QE}=6 \times \mathrm{CO}_{2}$-generation rate/absorption rate of incident photons, where the $\mathrm{CO}_{2}$-generation rate was obtained from the slope of the $\mathrm{CO}_{2}$-generation curve, which was calculated using the conventional least-squares method, as employed in previous reports. ${ }^{4), 12)-16)}$ The $\mathrm{CO}_{2}$-generation rate represents "overall photocatalytic activity" and the rate of incident-photon absorption is a measure of "visible-light absorption capability". Thus, we will discuss the results presented in Fig. 6 and Table 2 based on the assumption that "overall photocatalytic activity" = "QE" $\times$ "visible-light absorption capability". ${ }^{20)}$

The QE values for the Cu-grafted photocatalysts decreased with increasing $x$ values from 0 to 0.05 . This phenomenon is frequently encountered for photocatalysts because dopants can act as impurities that negatively impact hole and electron transports. ${ }^{4), 21), 22)}$ As dopants typically serve as recombination centers for holes and electrons, the efficiency of utilization of photogenerated electron-hole pairs, which is reflected in the QE, decreases. In contrast, dopants increase visible-light absorption capability compared to non-doped materials. For the $\mathrm{Cu}(\mathrm{II}) /$ $\mathrm{Ti}_{1-3 x} \mathrm{~W}_{x} \mathrm{Ga}_{2 x} \mathrm{O}_{2}$ photocatalysts, the positive influence of the dopants dominated up to $x=0.03$, whereas the negative effect was more significant up to $x=0.05$. For this reason, the overall photocatalytic activity of the material increased up to $x=0.03$ and then decreased up to $x=0.05$.

Interestingly, the $\mathrm{QE}$ values of $\mathrm{Cu}$-grafted photocatalysts increased with increasing $x$ above $x=0.07$, while the visiblelight absorption capability of the material was maintained. Thus, the overall photocatalytic activity increased. At present, we are unable to explain this phenomenon; however, it is possible that the density of states of the W $5 \mathrm{~d}$ orbital increased, thereby enhancing the contribution of the $\mathrm{W} 5 \mathrm{~d}$ orbital to the $\mathrm{CB}$, which is composed of $\mathrm{W} 5 \mathrm{~d}$ and $\mathrm{Ti} 3 \mathrm{~d}$ hybrid orbitals, and increasing the mobility of the photo-excited electrons in the CB. This would allow the electrons to more easily diffuse to the surface, where they would be captured effectively by $\mathrm{Cu}$ (II). As a result, the possibility of hole-electron recombination decreased and generated holes could be effectively utilized to oxidize 2-propanol. Thus, the $\mathrm{CB}$ control of $\mathrm{TiO}_{2}$ contributed to the increase in both QE and visible-light absorption, leading to the enhanced overall photocatalytic activity of $\mathrm{Cu}(\mathrm{II}) / \mathrm{Ti}_{1-3 x} \mathrm{~W}_{x} \mathrm{Ga}_{2 x} \mathrm{O}_{2}$. 


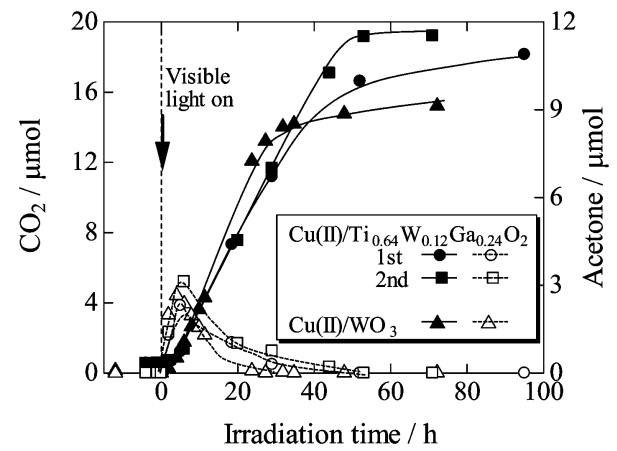

Fig. 7. Changes in acetone and $\mathrm{CO}_{2}$ amounts as a function of time during 2-propanol oxidation by $\mathrm{Ti}_{1-3 x} \mathrm{~W}_{x} \mathrm{Ga}_{2 x} \mathrm{O}_{2}(x=0.12)$ and $\mathrm{Cu}(\mathrm{II}) /$ $\mathrm{WO}_{3}$. The 2-propanol oxidation tests were repeated twice.

In Fig. 7, the results of 2-propanol decomposition tests performed under identical conditions as those described above are presented for $\mathrm{Cu}(\mathrm{II}) / \mathrm{Ti}_{1-3 x} \mathrm{~W}_{x} \mathrm{Ga}_{2 x} \mathrm{O}_{2}(x=0.12)$, in which $\mathrm{Cu}$ (II) was grafted onto $\mathrm{Ti}_{1-3 x} \mathrm{~W}_{x} \mathrm{Ga}_{2 x} \mathrm{O}_{2}$ after $\mathrm{HCl}$ treatment (Fig. 7). With $\mathrm{HCl}$ treatment, the $\mathrm{CO}_{2}$-generation rate increased from 0.30 to $0.40 \mu \mathrm{mol} / \mathrm{h}$, as shown in Table 2. Note that the $\mathrm{CO}_{2}$-generation rate was similar between two independent tests. To prepare the photocatalyst, we utilized starting materials that contained sodium ions $\left(\mathrm{Na}^{+}\right)$, which are well known to reduce photocatalytic activity if they remain in the photocatalysts. Thus, we used $\mathrm{HCl}$ treatment in an attempt to remove any remaining $\mathrm{Na}^{+}$ions. After irradiation of $\mathrm{HCl}$-treated $\mathrm{Cu}(\mathrm{II}) /$ $\mathrm{Ti}_{1-3 x} \mathrm{~W}_{x} \mathrm{Ga}_{2 x} \mathrm{O}_{2}(x=0.12)$ for $50-80 \mathrm{~h}$, nearly $18 \mu \mathrm{mol} \mathrm{CO} \mathrm{CO}_{2}$ was produced, indicating complete oxidation of the injected $6.1 \mu \mathrm{mol}$ 2-propanol. As a comparsion, the 2-propanol decomposition test was also performed for commercially available $\mathrm{Cu}$ (II)-grafted tungsten trioxide $\left[\mathrm{Cu}(\mathrm{II}) / \mathrm{WO}_{3}\right.$, HP-CW091, Showa Denko K.K.] (Fig. 7). The $\mathrm{CO}_{2}$-generation rate of $\mathrm{Cu}(\mathrm{II}) / \mathrm{WO}_{3}(0.48 \mu \mathrm{mol} / \mathrm{h}$, Table 2) was superior to that of $\mathrm{Cu}(\mathrm{II}) / \mathrm{Ti}_{1-3 x} \mathrm{~W}_{x} \mathrm{Ga}_{2 x} \mathrm{O}_{2} \quad(x=$ $0.12,0.40 \mu \mathrm{mol} / \mathrm{h})$, indicating that the visible-light absorption capability of the $\mathrm{Cu}(\mathrm{II}) / \mathrm{WO}_{3}$ system compensated for the lower $\mathrm{QE}$ value to a greater extent than that of $\mathrm{Cu}(\mathrm{II}) / \mathrm{Ti}_{1-3 x} \mathrm{~W}_{x} \mathrm{Ga}_{2 x} \mathrm{O}_{2}$ $(x=0.12)$. More importantly, the amount of rare-metal $\mathrm{W}$ could be reduced if $\mathrm{TiO}_{2}$ was utilized as a mother structure and its electronic band structure was controlled to resemble that of $\mathrm{WO}_{3}$. As mentioned above, the surface area of $\mathrm{Ti}_{1-3 x} \mathrm{~W}_{x} \mathrm{Ga}_{2 x} \mathrm{O}_{2}$ $(x=0.12)$ is relatively small $\left(2.56 \mathrm{~m}^{2} / \mathrm{g}\right)$ following calcination at $780^{\circ} \mathrm{C}$ for $24 \mathrm{~h}$; thus, we speculate that the overall photocatalytic activity could be further increased to exceed that of $\mathrm{Cu}(\mathrm{II}) / \mathrm{WO}_{3}$ by adjusting the calcination conditions to increase the $\mathrm{QE}$.

\section{Conclusions}

We prepared CB-controlled $\mathrm{Ti}_{1-3 x} \mathrm{~W}_{x} \mathrm{Ga}_{2 x} \mathrm{O}_{2}$ photocatalysts up to $x=0.12$ with an optical band gap energy of $\sim 2.8 \mathrm{eV}$. The observed action spectrum for $\mathrm{O}_{2}$ evolution confirmed that the band gap of the prepared materials underwent narrowing. $\mathrm{Ti}_{1-3 x} \mathrm{~W}_{x} \mathrm{Ga}_{2 x} \mathrm{O}_{2}$ photocatalysts grafted with $\mathrm{Cu}$ (II) effectively decomposed 2-propanol to $\mathrm{CO}_{2}$ under visible light. Our findings clearly demonstrate that the $\mathrm{CB}$ control of $\mathrm{TiO}_{2}$ contributes to an increase in both QE and visible-light absorption, leading to a marked increase in overall photocatalytic activity. In addition, $\mathrm{HCl}$ treatment enhanced the photocatalytic activity of $\mathrm{Ti}_{1-3 x} \mathrm{~W}_{x^{-}}$ $\mathrm{Ga}_{2 x} \mathrm{O}_{2}(x=0.12)$. To further enhance the visible light-induced activity of this system, optimization of the calcination conditions is necessary to increase the surface area of $\mathrm{Ti}_{1-3 x} \mathrm{~W}_{x} \mathrm{Ga}_{2 x} \mathrm{O}_{2}$.

Acknowledgements This work was mainly performed under the management of the Project to Create Photocatalyst Industry for Recycling-oriented Society supported by NEDO. This study was partially supported by the Cooperative Research Program of Catalysis Research Center, Hokkaido University (Grant \#11C3002) and JST, CREST. We express gratitude to Mr. G. Newton for the careful reading of the manuscript.

\section{References}

1) E. Borgarello, J. Kiwi, M. Gratzel, E. Pelizzetti and M. Visca, J. Am. Chem. Soc., 104, 2996-3002 (1982).

2) M. Anpo and M. Takeuchi, J. Catal., 216, 505-516 (2003).

3) R. Asahi, T. Morikawa, T. Ohwaki, K. Aoki and Y. Taga, Science, 293, 269-271 (2001).

4) H. Irie, Y. Watanabe and K. Hashimoto, J. Phys. Chem. B, 107, 5483-5486 (2003).

5) T. Ohno, T. Mitsui and M. Matsumura, Chem. Lett., 32, 364365 (2003).

6) S. Sakthivel and H. Kisch, Angew. Chem., Int. Ed., 42, 49084911 (2003).

7) M. Mrowetz, W. Balcerski and M. R. Hoffmann, J. Phys. Chem. B, 108, 17269-17273 (2004).

8) A. Hagfeldt and M. Grätzel, Chem. Rev., 95, 49-68 (1995).

9) E. Bae, W. Choi, J. Park, H. S. Shin, S. B. Kim and J. S. Lee, J. Phys. Chem. B, 108, 14093-14101 (2004).

10) H. Kisch, L. Zang, C. Lange, W. F. Maier, C. Antonius and D. Meissner, Angew. Chem., Int. Ed., 37, 3034-3036 (1998).

11) Y. Ishibai, J. Sato, S. Akita, T. Nishikawa and S. Miyagishi, J. Photochem. Photobiol., A, 188, 106-111 (2007).

12) H. Irie, S. Miura, K. Kamiya and K. Hashimoto, Chem. Phys. Lett., 457, 202-205 (2008).

13) H. Irie, K. Kamiya, T. Shibanuma, S. Miura, D. A. Tryk, T. Yokoyama and K. Hashimoto, J. Phys. Chem. C, 113, 1076110766 (2009).

14) H. Yu, H. Irie, Y. Shimodaira, Y. Hosogi, Y. Kuroda, M. Miyauchi and K. Hashimoto, J. Phys. Chem. C, 114, 1648116487 (2010).

15) K. Kamiya, S. Miura, K. Hashimoto and H. Irie, Electrochem., 79, 793-796 (2011).

16) H. Yu, H. Irie and K. Hashimoto, J. Am. Chem. Soc., 132, 6898-6899 (2010).

17) Y. I. Kim, S. J. Atherton, E. S. Brigham and T. E. Mallouk, J. Phys. Chem., 97, 11802-11810 (1993).

18) B. Ohtani, Chem. Lett., 37, 217-229 (2008).

19) Y. Ohko, K. Hashimoto and A. Fujishima, J. Phys. Chem. A, 101, 8057-8062 (1997).

20) F. Amano, K. Nogami and B. Ohtani, J. Phys. Chem. C, 113, 1536-1542 (2009).

21) H. Irie and K. Hashimoto, J. Am. Ceram. Soc., 88, 3137-3142 (2005).

22) H. Irie, Y. Maruyama and K. Hashimoto, J. Phys. Chem. C, 111, 1847-1852 (2007). 